Journal of Applied Pharmaceutical Science Vol. 7 (07), pp. 098-102, July, 2017

Available online at http://www.japsonline.com

DOI: $10.7324 /$ JAPS.2017.70715

ISSN 2231-3354 (cc) BY-NC-SA

\title{
In Vitro Micropropagation of Anisochilus carnosus (L) Wall
}

\author{
N. A. Reshi ${ }^{*}$ M. S. Sudarshana, H. V. Girish \\ Department of Studies in Botany, University of Mysore, Mysore, Karnataka, India.
}

\begin{tabular}{|c|c|}
\hline ARTICLE INFO & ABSTRACT \\
\hline Article history: & \multirow{9}{*}{$\begin{array}{l}\text { The present study describes a protocol for the in vitro mass propagation of Anisochilus carnosus (L) Wall - an } \\
\text { anticancer ethnomedicinal herb. Young and healthy leaf segments were inoculated on to the solid Murashige and } \\
\text { Skoog (MS) medium supplemented with different auxins and cytokinins individually and in combination. } \\
\text { Maximum callusing percentage ( } 97 \% \text { ) was achieved in MS medium fortified with } 2,4 \text {-Dichlorophenoxyacetic } \\
\text { acid (2,4-D) at } 5 \mathrm{mg} / \mathrm{l} \text {. Multiple shoots were achieved in benzylaminopurine (BAP) and Indole-3 acetic acid } \\
\text { (IAA) combination with maximum of } 14 \pm 0.23 \text { shoots per culture at } 7 \mathrm{mg} / \mathrm{l} \text { BAP }+3.5 \mathrm{mg} / 1 \mathrm{IAA} \text { concentration. } \\
\text { For } \text { in vitro rhizogenesis, elongated micro shoots were aseptically excised and transferred to the half strength } \\
\text { MS liquid medium enriched with different auxins. Out of the different auxins tested, indole butyric acid (IBA) } \\
\text { was found to be the best for rhizogenesis at } 2 \mathrm{mg} / 1 \text { with maximum of } 11 \pm 0.45 \text { roots per shoot. The well } \\
\text { established rooted plantlets were hardened under laboratory conditions for two weeks by transferring to the poly } \\
\text { cups containing vermicompost and sterile soil in the ratio of } 1: 1 \text {. The hardened plantlets were transferred to the } \\
\text { green house for two weeks and finally to the filed with } 90 \% \text { survivability. }\end{array}$} \\
\hline Received on: 15/01/2017 & \\
\hline Accepted on: $24 / 03 / 2017$ & \\
\hline Available online: $30 / 07 / 2017$ & \\
\hline Key words: & \\
\hline Leaf segments, Callusing, & \\
\hline Multiple shoots, & \\
\hline Rhizogenesis, & \\
\hline Acclimatisation, A. carnosus. & \\
\hline
\end{tabular}

\section{INTRODUCTION}

India is a treasure house of 47,000 species of Angiosperms, out of which a total of 560 plant species have been recognised as threatened species by IUCN (Bapat et al., 2008). Health consciousness and harsh side effects of non-natural products have made the natural plant products a common man's preference. Different traditional health care systems exist among different tribes and geographical regions. Among the continents, Asia is a treasure of knowledge with regard to the use of plants in treatment of various ailments. In India, among the major systems of indigenous medicines, i.e. Ayurveda, Siddha, Unani and Folk (tribal), Ayurveda is developed most and widely accepted and practiced (Kunwar and Rainer, 2008). In recent years, traditional

* Corresponding Author

Nissar Ahmad Reshi, Research Scholar, Department of Studies in

Botany, University of Mysore, Mysore, Karnataka, India - 570006

Email: nissarreshi @ gmail.com; Mobile: +91-7411564637 medicine has become a topic of global importance as the modern man prefers herbal medicine over others. The surge of public interest in herbal medicine tied with rapid expansion of pharmaceutical industries and more importantly the unrestricted collection of medicinal plants from wild in destructive and unsustainable manner has put the wild medicinal plant population in dwindling mode. The wild population of medicinal plants has drastically come down which is the grave issue to be addressed (Thomas, 1997). It is being held that number of multipurpose ethnomedicinal plants have become either endangered or are under extinction threat in tropical ecosystems of developing countries.

Owing to the high demand of medicinal plants and a subsequent threat, a lot of attention is being paid to the plant tissue technique to arrest this threat. The over exploitation of medicinal plants stipulates the establishment of in vitro tissue culture conditions for the rapid and mass propagation of medicinal plants. Plant tissue culture is the most convenient and effective strategic way for germplasm conservation and rapid multiplication of medicinally important plant species to cater the present pharmaceutical demands and ensures no damage is done to the natural plant population. 
A. carnosus (L) Wall.is an annual herb, $30-60 \mathrm{~cm}$ tall, robust and branched with fleshy leaves. It grows in the Asia continent of Hong Kong, Macao, Shangai, Tianjin, India, Myanmar and Sri Lanka. It is an multipurpose ethnomedicinal plant used for the treatment of different ailments like gastrointestinal disorders, respiratory disorders, cough, cold and fever (Kamble et al., 2008). Its formulation with Ocimum basilicum, Mentha piperita and Alpinia galanga has been reported to treat skin inflammation and influenza (Subramanian and Nair, 1972). Essential oils have been extracted by hydrodistillation from the leaves and have been reported to be antimicrobial in nature (Senatore et al., 2003). The plant has been reported to have antiinflammatory activity (Grover et al., 2001), antiulcer activity (Mohammed et al., 2008), antifungal property (Kulandhaivel et al., 2011) and anticancer property (Muthuraman et al., 2012). Due to multipurpose medicinal nature of A. carnosus and the stress from pharmaceutical industries, the present study was aimed to standardize a protocol for its in vitro mass propagation.

\section{MATERIALS AND METHODS}

Anisochilus carnosus plants were collected from Western Ghats, Tamil Nadu, India and are being maintained in the medicinal plant garden of the Department of Studies in Botany, University of Mysore, Mysuru. Young and healthy leaf explants were collected from the garden and were washed under running tap water for ten minutes to remove the soil and dust exudates. The explants were then treated with `fungicide bavistin $(5 \% \mathrm{w} / \mathrm{v})$ for 5 minutes followed by dipping in $70 \%$ alcohol for $30-40$ seconds and were then washed with sterile double distilled water. Inside the laminar air flow explants were treated with $0.01 \% \mathrm{HgCl}_{2}$ for 5 minutes followed by washing thrice with sterile double distilled water. The surface sterilised leaf explants were cut into small pieces $(1-2 \mathrm{sq} . \mathrm{cm})$ and inoculated on to the solid MS medium containing 3\% sucrose, gelled with $0.08 \%$ agar and fortified with different combinations and concentrations of growth regulators. The $\mathrm{pH}$ of the medium was adjusted to 5.8 prior to autoclaving at $121^{\circ} \mathrm{C}$ for 15 minutes. The cultures were incubated at $22 \pm 2^{\circ} \mathrm{C}$ with 16 hour photoperiod under light florescent tubes with light intensity of $25 \mu \mathrm{mol} / \mathrm{s}^{2} / \mathrm{m}^{2}$ for 4 weeks. In vitro regenerated shoots after attaining a height of 3-5 cm were aseptically transferred to half strength MS liquid medium supplemented with different auxins. Root length and number of roots per shoot data was collected after 4 weeks. After 4 weeks well rooted micro shoots were hardened under laboratory conditions for 2 weeks by transferring to the polycups containing vermicompost and sterile soil in the ratio of $1: 1$. The hardened plantlets then were transferred to the green house for two weeks and then to the garden with $90 \%$ survivability.

\section{RESULTS}

\section{Callus induction}

After two weeks of inoculation, callus initiation was reported along the cut edges of leaf explants. When leaf explants were placed onto the MS medium either on its adaxial or abaxial surface, callus was first reported from the abaxial surface. Explants showed curling and along the cut edges turned into creamy colour and the callus was induced. Explants were tested on MS medium supplemented with different concentrations of auxins (0.5-5 mg/l) for callus induction(Fig. 1a).

Almost all the auxin concentrations tested produced callus on MS medium. Best callusing response was reported in MS medium supplemented with 2, 4-D at $5 \mathrm{mg} / \mathrm{l}$ concentration. On combination of BAP with different auxins, callusing was achieved in all combinations of BAP with 2,4-D, IAA, NAA (naphthalene acetic acid) and IBA. Effect of different auxins alone and in combination with BAP callus induction of leaf explants of $A$. carnosus is given in Table $\mathbf{1}$.

\section{Induction of multiple shoots}

Leaf explants callused moderately and then produced shoot buds which later proliferated into multiple shoots with maximum number of $14 \pm 0.76$ shoots per culture (Fig.1b; 1c). The best combination for multiple shoot induction was found to be BAP in combination with IAA and NAA. The effect of BAP in combination with auxins on multiple shoot induction is presented in Table 2 .

Table 1: Effect of growth regulators on callus induction of leaf explants in A. carnosus.

\begin{tabular}{|c|c|c|c|c|c|c|c|c|c|c|}
\hline $\begin{array}{c}\text { Conc. } \\
\text { mg/l }\end{array}$ & 2,4-D & IAA & NAA & IBA & BAP & $\begin{array}{c}\text { Conc. } \\
\mathrm{mg} / \mathrm{l}\end{array}$ & BAP+2,4-D & BAP+IAA & BAP+NAA & $\mathrm{BAP}+\mathrm{IBA}$ \\
\hline \multicolumn{7}{|c|}{ Percentage Callusing } & \multicolumn{4}{|c|}{ Percentage Callusing } \\
\hline 0.5 & 38 & -- & -- & -- & -- & $1+0.5$ & 40 & 20 & 15 & 10 \\
\hline 1 & 46 & -- & -- & -- & -- & $2+1$ & 66 & 22 & 10 & 18 \\
\hline 1.5 & 55 & -- & -- & -- & 15 & $3+1.5$ & 80 & 30 & 23 & 20 \\
\hline 2 & 68 & -- & -- & 21 & 18 & $4+2$ & 85 & 46 & 27 & 32 \\
\hline 2.5 & 82 & 50 & 36 & 32 & 35 & $5+2.5$ & 88 & 53 & 35 & 35 \\
\hline 3 & 87 & 62 & 41 & 32 & 48 & & & & & \\
\hline 3.5 & 93 & 70 & 50 & 45 & 55 & & & & & \\
\hline 4 & 90 & 70 & 54 & 52 & 60 & & & & & \\
\hline 4.5 & 92 & 72 & 59 & 55 & 68 & & & & & \\
\hline 5 & 97 & 80 & 64 & 61 & 78 & & & & & \\
\hline
\end{tabular}

${ }^{*}$ All the growth regulator treatments to leaf explant were in 6 replicates and were repeated thrice; callusing percentage $=($ Nu mber of explants callused/ Total number of explants inoculated) $\times 100$ 
Table 2: Effect of growth regulators on multiple shoot induction in A. carnosus leaf explants.

\begin{tabular}{|c|c|c|c|}
\hline Growth Regulator & Concentration (mg/l) & Mean shoot number & Mean Shoot length \\
\hline \multirow{4}{*}{ BAP } & 1 & -- & -- \\
\hline & 3 & -- & -- \\
\hline & 5 & -- & -- \\
\hline & 7 & -- & -- \\
\hline \multirow{4}{*}{$\mathrm{BAP}+2,4-\mathrm{D}$} & $1+0.5$ & -- & -- \\
\hline & $3+1.5$ & -- & -- \\
\hline & $5+2.5$ & -- & -- \\
\hline & $7+3.5$ & -- & -- \\
\hline \multirow{4}{*}{$\mathrm{BAP}+\mathrm{IAA}$} & $1+0.5$ & -- & -- \\
\hline & $3+1.5$ & $6 \pm 0.56$ & $4.25 \pm 0.58$ \\
\hline & $5+2.5$ & $14 \pm 0.76$ & $4.88 \pm 0.42$ \\
\hline & $7+3.5$ & $7 \pm 0.43$ & $4.45 \pm 0.65$ \\
\hline \multirow{4}{*}{$\mathrm{BAP}+\mathrm{NAA}$} & $1+0.5$ & -- & -- \\
\hline & $3+1.5$ & $5 \pm 0.52$ & $3.24 \pm 0.54$ \\
\hline & $5+2.5$ & $5 \pm 0.41$ & $4.41 \pm 0.38$ \\
\hline & $7+3.5$ & $4 \pm 0.51$ & $4.67 \pm 0.21$ \\
\hline \multirow{4}{*}{$\mathrm{BAP}+\mathrm{IBA}$} & $1+0.5$ & -- & -- \\
\hline & $3+1.5$ & -- & -- \\
\hline & $5+2.5$ & -- & -- \\
\hline & $7+3.5$ & -- & -- \\
\hline
\end{tabular}

*All the growth regulator treatments to leaf explant were in 6 replicates and were repeated thrice. Each value represents Mean \pm S.D. Statistical analysis using DMRT $(\mathrm{P} \leq 0.5)$.
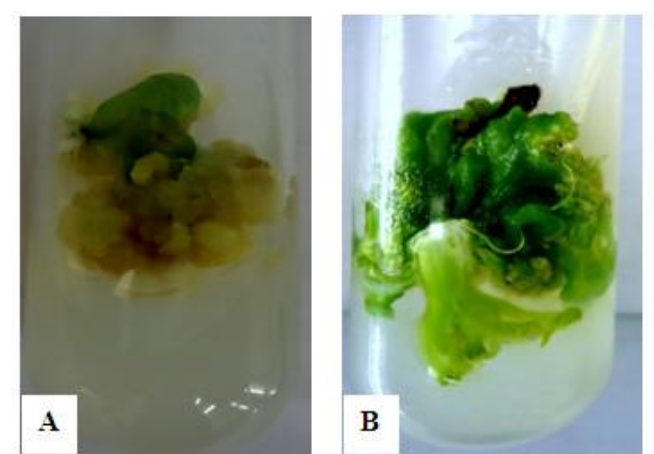

Fig.1. a) Leaf callusing at $5 \mathrm{mg} / 1$ 2,4-D; b\& c) Multiple shoot
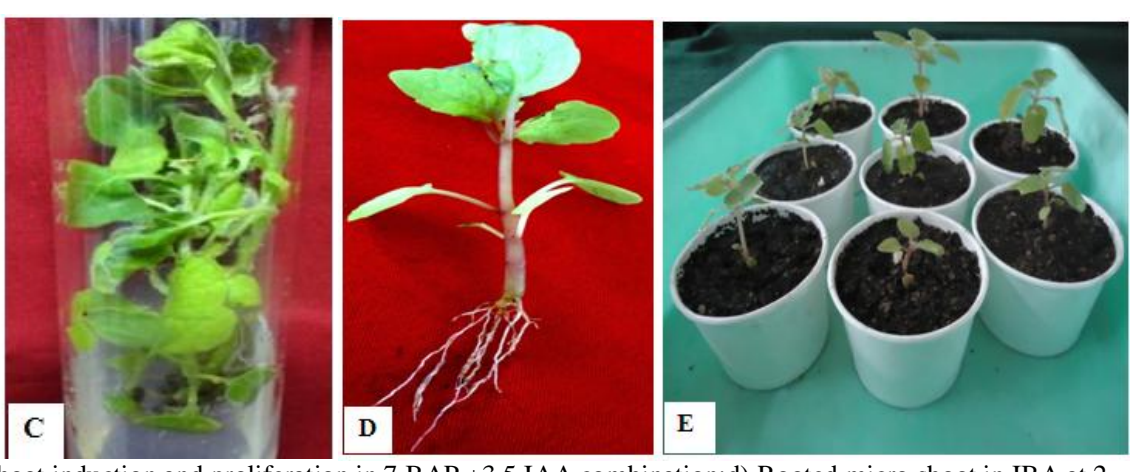

$\mathrm{mg} / \mathrm{l}$; e) Acclimatised plantlets.

Table 3: Effect of auxins on in vitro rhizogenesis of regenerated shoots from A. carnosus.

\begin{tabular}{|c|c|c|c|c|}
\hline Growth regulator & Concentration mg/l & Mean no. of roots per shoot & Mean root length & Percent shoots forming roots \\
\hline \multirow{6}{*}{ IAA } & 0.5 & -- & -- & -- \\
\hline & 1 & -- & -- & -- \\
\hline & 1.5 & -- & -- & -- \\
\hline & 2 & -- & -- & -- \\
\hline & 2.5 & -- & -- & -- \\
\hline & 3 & -- & -- & -- \\
\hline \multirow{6}{*}{ IBA } & 0.5 & -- & -- & -- \\
\hline & 1 & -- & -- & -- \\
\hline & 1.5 & $3.6 \pm 0.56$ & $2.42 \pm 0.63$ & 82 \\
\hline & 2 & $11.21 \pm 0.69$ & $3.67 \pm 0.41$ & 95 \\
\hline & 2.5 & $4.5 \pm 0.34$ & $2.02 \pm 0.48$ & 70 \\
\hline & 3 & -- & -- & -- \\
\hline \multirow{6}{*}{ NAA } & 0.5 & -- & -- & -- \\
\hline & 1 & -- & -- & -- \\
\hline & 1.5 & -- & -- & -- \\
\hline & 2 & -- & -- & -- \\
\hline & 2.5 & -- & -- & -- \\
\hline & 3 & -- & -- & -- \\
\hline
\end{tabular}

*All the growth regulator treatments to micro shoots were in 6 replicates and were repeated thrice. Each value represents Mean \pm S.D. Statistical analysis using $\operatorname{DMRT}(\mathrm{P} \leq 0.5)$. 


\section{Rhizogenesis}

Well elongated in vitro regenerated micro shoots were aseptically removed from the culture flasks and transferred to the MS half strength liquid medium supplemented with different auxins. Micro shoots developed in vitro roots in MS medium fortified with IBA at $2 \mathrm{mg} / \mathrm{l}$, inducing roots in 3 weeks with maximum of $11 \pm 0.21$ roots per shoot (Fig.1d; Table 3). At higher concentrations of IBA (above $2 \mathrm{mg} / \mathrm{l}$ ), basal callusing was reported with stunted shoot growth.

\section{Hardening of regenerated plantlet}

Well developed in vitro rooted plantlets were taken out carefully from the culture tubes and were transferred to the poly cups containing vermicompost and sterile soil in the ration of 1:1 and were hardened under laboratory conditions for two weeks (Fig. 1e ). After hardening, plantlets were transferred to the green house for two weeks. Fully acclimatised and grown plantlets were finally transferred to the bigger pots and maintained under natural conditions in the garden where $90 \%$ of the plantlets survived.

\section{DISCUSSION}

The aim of the tissue culture studies is to standardise the in vitro conditions for the rapid and mass propagation of the medicinally important plants. In our study, leaf explants responded to callusing differently on different growth regulator concentrations and combinations. Best callus induction was achieved from leaf explants on MS medium containing either auxins alone or in combination with BAP. Out of the auxins used, 2,4-D was found to be the best for callus induction. Similar response of higher callus induction from leaf explants in 2,4-D supplemented MS medium has been reported earlier in Cichorium intybus (Nandagopal and Ranjithakumari, 2006) and Clematis gouriana (Raja and Krishna, 2007). 2,4-D has been reported to be the determining factor in active cell division and is the most effective auxin in callus induction as reported earlier by Sudarshana and Shanthamma, (1991), Pretto and Santarem, (2000) and Vengadesan et al., (2000). MS medium supplemented with BAP in combination with different auxins produced callusing, however BAP + 2,4-D proved to be the best callus inducing combination. Similar results have been reported earlier in Beloperone plumbaginifolia (Shameer et al., 2009), Momordica dioica (Davendra et al 2009), Arnica montana (Petrova et al., 2011) and Coccinia abyssinica (Tola et al., 2015); however our studies contradict with the Chaitali et al., (2014) who reported BAP in combination with IBA as the best combination for callus induction in Spilanthes acmella.

Multiple shoot induction was achieved in MS medium supplemented with BAP in combination IAA and NAA. Higher concentration of cytokinins (BAP) and lower concentrations of auxins promote organogenesis as described earlier by Kelkar et al., (1996) in Piper colubrinum, Kavitha et al., (2001) in Pearl millet and Matheew et al. (2015) in Vanilla tahitensis. Primarily, cytokininins have major role on plant development, such as regulation of shoot formation, multiplication and the promotion of cell division and expansion (Mok and Mok, 2001).Our results concur with the studies carried out earlier in Zingiber officinale (Kirmal et al., 1992), Curcuma longa (Neeta et al., 2000) and Gynandropsis pentaphylla (Nagarathnamma et al., 2013). In the present study our results revealed that the effect of BAP and auxin combination on multiple shoot induction is more compared to BAP or auxins when used separately. This is in confirmation with the earlier studies in Bambusa glaucescens (Shirin and Rana, 2007) and Lagenaria siceraria (Saha et al., 2007). For in vitro rhizogenesis, IBA at $2 \mathrm{mg} / \mathrm{l}$ concentration induced maximum number of roots while simultaneously improving the growth of micro shoots. Our results are in accordance with the studies carried out on Thapsia garganica (Mukunga et al., 2006), Pseudarthria viscid (Vinothkumar et al., 2010), Cassia angustifolia (Parveen and Shahzad, 2011) and Solanum nigrum (Sridhar and Naidu, 2011). The superiority of IBA over other auxins for root induction has been earlier reported in Cajanus cajan (Dayal et al., 2003), Murraya koenigii (Rout, 2005) and Quill resiliencies (Fleck et al., 2009).

\section{CONCLUSION}

The present study describes the standardized protocol for the callus induction and in vitro propagation of A. carnosus using leaf explants. The study revealed that leaf is the useful explant for the mass propagation of this plant. The standardized protocol in the present study could be employed for the mass propagation of such highly valuable medicinal plant and could negate the threat to the wild existence while simultaneously will meet the pharmaceutical demands.

\section{ACKNOWLEDGEMENT}

Authors express their gratefulness to the University of Mysore for providing all the necessary facilities to carry out this research work.

Conflict of interest: The authors declare that they do not have any conflict of interest.

\section{REFERENCES}

V. A. Bapat, S. R. Yadav, G. B. Dixit. Rescue of endangered plants through biotechnology applications. National Academy Science Letters. 2008; 31(9), 201-10.

N. Chaitali, S. Malti, T. Preeti. Callus induction and plant regeneration from leaf explants of Spilanthes acmella Murr: An endangered medicinal plant. Annals of Biological Research. 2014; 5(9), 66-71.

N. K. Davendra, B. Subhash, Y. N. Seetharam. Callus growth and plant regeneration in Momordica dioica (Roxb.) Wild. Cucurbitaceae. American-Eurasian Journal of Sustainable Agriculture. 2009; 3(4), 743 748.

S. Dayal, M. Lavanya, P. Devi, K. K. Sharma. An efficient protocol for shoot regeneration and genetic transformation of pigeon pea (Cajanus cajan (L) Mill sp.) using leaf explants. Plant Cell Reports. 2003; 21(7), 1072-1079. 
J. D. Fleck, J. Schwambach, M. E. Almeida, A. C. A. Yendo, F. de-Costa, G. Gosmann, A. G. Fett-Neto. Immuno adjuvant saponin production in seedlings and micropropagated plants of Quillaja brasiliensis. In vitro Cellular and Development Biology-Plant. 2009; 45(7), 715-720.

J. K. Grover, G. Adiga, V. Vata, S. S. Rathi. Extracts of Anisochilus carnosus prevent development of experimental inflammation. Journal of Ethanopharmacy. 2001; 7(8), 159-164.

S. Y. Kamble, T. N. More, S. R. Patil, S. G. Pawar, R. Bindurani, S. L. Bodhankar. Plants used by the tribes of Northwest Maharashtra for the treatment of gastrointestinal disorders. Indian Journal of Traditional Knowledge. 2008; 7(2), 321-325.

P. Kavitha, N. M. Ramaswamy, D. Punitha, N. Devasena, K. N. Yamini. In vitro callus induction and plantlets regeneration from young inflorescence and leaf explants of Pearl millet.Plant Cell Biotechnology and Moecularl Boilogy. 2001; 2(1\&2), 33-40.

S. M. Kelkar, G. B. Deboo, K. V. Krishnamurthy. In vitro plant regeneration from leaf callus in Piper colubrinum Link. Plant Cell Reports. 1996; 16(4), 215-218.

B. N. Kirmal, K. Samsudeen, P. N. Ravindran. Direct regeneration of plantlets from inflorescence of ginger (Zingiber officinalis Rosc) by Tissue Culture. Journal of Spices and Aromatic Crops. 1992; $1(5), 43-48$

M. Kulandhaivel, S. N. Sooraj, K. Nathiya, M. Palaniswamy. Antifungal activity and phytochemical screening of Anisochilus carnosus and Melaleuca alternifolia against opportunistic pathogen Candida albicans. International Journal of Pharmaceutical and Biological Archives. 2011; 2(6), 1668-1670.

R. M. Kunwar, B. W. Rainer. Ethnobotany in the Nepal Himalaya.Journal of Ethnobiology and Ethnomedicine. 2008; 4(24), 4-24.

K. M. Matheew, Y. S. Rao, G. L. George, R. Lakshmanan, K. J. Madhusoodanan. In vitro propagation of Vanilla tahitensis Moore. Journal of Spices and Aromatic Crops. 2015; 9(2), 421-426.

A. Mohammed, R. J. Kumar, H. Y. Santosh, M. H. Nagashruthi. Antiulcer activity of Anisochilus carnosus leaf extracts in pylorus ligation rats. Indian Drugs. 2008; 45(12), 979-983.

D. W. S. Mok, M. C. Mok. Cytokinin metabolism and action. Annual Review of Plant Physiology and Plant Molecular Biology. 2001; 52(8), 89-118.

N. P. Mukunga, A. K. Jeger, J. V. Staden. Improved in vitro rooting and hyperhydracity in regenerating tissues of Thapsia garganica L. Plant Cell Tissue and Organ Culture. 2006; 16(8), 77-86.

M. S. Muthuraman, L. Santharam, S. Ariraman, B. Pemaiah. Studies on anticancer and antimicrobial efficacy of Anisochilus carnosus extracts. International Journal of Pharmacy and Pharmaceutical Science. 2012; 4(2), 132-135.

M. Nagarathnamma, M. S. Sudarshana, M. H. Niranjana. Plant regeneration from inflorescence explants of Gynandropsis pentaphylla. Journal of Pharmaceutical Sciences. 2013; 3(1), 153-155.

S. Nandagopal, B.D. Ranjitha Kumari. Adenine sulphate induced high frequency high shoot organogenesis in callus and in vitro flowering of Cichorium intybus -a potent medicinal plant. Acta Agriculturae Slovenica. 2006; 87(2), 415-425.

D. S. Neeta, G. Leela, E. Susan. Direct regeneration of shoots from immature inflorescence cultures of turmeric. Plant Cell Tissue and Organ Culture. 2000; 14(2), 235-238.

S. Parveen, A. Shahzad. A micropropagation protocol for Cassia angustifolia Vahl.from root explants. Acta Physiologiae Plantarum.2011; 33(8), 789-796
M. Petrova, E. Zayova, E. Yankova, G. Baldzhiev. Plant regeneration from callus culture of Arnica montana. Romanian Biotechnology Letters. 2011; 16(1), 92-97.

F. R. Pretto, E. R. Santarem. Callus formation and plant regeneration from Hypericum perforatum leaves. Plant Cell Tissue and Organ Culture. 2000; 62(2), 107-113.

N. H. Raja, V. Krishna. Plant regeneration from callus cultures of Clematis gouriana Roxb. A rare medicinal plant. Turkish Journal of Botany. 2007; 13(9), 9-103.

G. R. Rout. Direct plant regeneration of curry leaf tree (Murraya koenigii Konig.) an aromatic plant. In vitro Cellular and Developmental Biology-Plant. 2005; 42(7), 133-136.

S. Saha, H. Mori, K. Hattori. Synergistic effect of kinetin and benzyl adenine plays a vital role in high frequency regeneration from cotyledon explants of bottle gourd (Lagenaria siceraria) in relation to ethylene production. Breeding Science. 2007; 15(7), 197-202.

F. Senatore, L. Francesca, F. Venza, M. Bruno, F. Napolitano. Composition and antibacterial activity of the essential oil of Anisochilus carnosus- a Tamil plant acclimatized in Sicily. Flavour and Fragrance Journal. 2003; 18(8), 202-204.

M. C. Shameer, V. P. Saeeda, P. V. Madhusoodanan, S. Benjamin. Direct organogenesis and somatic embryogenesis in Beloperone plumbaginifolia (Jacq.) Nees. Indian Journal of Biotechnology. 2009; 8(7), 132-135.

F. Shirin, P. K. Rana.In vitro plantlet regeneration from nodal explants of field grown culms in Bambusa glaucescens wild. Plant Biotechnology Reports.2007; 8(7), 141-7.

T. M. Sridhar, C. V. Naidu. An efficient callus induction and plant regeneration of Solanum nigrum (L)-an important antiulcer medicinal plant. Journal of Phytology. 2011;3(5), 23-28.

S. S. Subramanian, A. G. R. Nair. Flavonoids of the leaves of Mentha spicata and Anisochilus carnosus. Phytochemistry. 1972; 11(1), 452-453.

M. S. Sudarshana, C. Shanthamma. In vitro regeneration from excised leaves of Flaveria trinervia. Plant Cell Tissue and Organ Culture. 1991; 27(6), 297-302.

J. Thomas. Medicinal and aromatic plants research in India UNDP.1997. Proc. Training course on Industrial Exploitation of Indigenous Medicinal and Aromatic Plants. Beijing, China. 1997; 17-27.

B. G. Tola, J. Kahia, J. Onguso, N. K. Peter. Standardization of in vitro sterilization and callus induction protocol for leaf explants of anchote: Coccinia abyssinica. International Journal of Research and Development in Pharmacy and Life Sciences. 2015; 4(2), 1427-1433

G. Vengadesan, A. Ganapathi, R. P. Anand, V. R. Anbazhagan In vitro organogenesis and plant formation in Acacia sinuata. Plant Cell Tissue and Organ Culture. 2000; 61(1), 23-28

D. Vinothkumar, S. Senthil Kumar, S. Murugavel. Micropropagation of Pseudarthira viscid L., from nodal explants-A Medicinal Plant. Journal of Advanced Biotechnology. 2010; 10(4), 16-18

\section{How to cite this article:}

Reshi NA, Sudarshana MS, Girish HV. In Vitro Micropropagation of Anisochilus carnosus (L) Wall. J App Pharm Sci, 2017; 7 (07): 098-102. 